\title{
Transitioning to online education in English departments in Bangladesh: Learner perspectives
}

\author{
Ahmed Bashir, Md. Elias Uddin, Bijoy Lal Basu, and Rubina Khan \\ Department of English, University of Dhaka, Dhaka 1000, Bangladesh
}

\begin{abstract}
During the brief coronavirus-induced hiatus in March and April 2020, educational institutions in Bangladesh including public universities began preparations for online classes. By the end of June, almost all private universities and a few public universities had started online classes with limited or no preparation, which was met with appreciation as well as censure from different stakeholders. Against this backdrop, this study was conducted with a view to examining the online teaching-learning scenario at Bangladeshi public universities from the perspective of one important stakeholder, the students, with a specific focus on the challenges they faced with this new mode of instruction. Suggestions were also sought from them regarding how the barriers to online instruction could be overcome. Data were collected from 26 students of English Departments of 11 public universities through semi-structured interviews. The major challenges reported include issues of access and equity, inadequate logistic support and poor infrastructure. Concerns related to curriculum, pedagogy, assessment and psychological issues were also highlighted. In addition, lack of prior experience and inadequate training were identified as serious obstacles. Major suggestions from the participants include ensuring access and equity, providing training opportunities and digital devices to students, and engaging in curriculum and assessment reforms.
\end{abstract}

Keywords: Challenges; COVID-19; higher education; learner perspectives; online education; suggestions

\begin{tabular}{lcc}
\hline First Received: & Revised: & Accepted: \\
6 January 2021 & 18 March 2021 & 4 April 2021 \\
Final Proof Received: & & Published: \\
23 May 2021 & & 31 May 2021 \\
\hline
\end{tabular}

How to cite (in APA style):

Bashir, A., Uddin, M. E., Basu, B. L., Khan, R. (2021). Transitioning to online education in English Departments in Bangladesh: Learner perspectives. Indonesian Journal of Applied Linguistics, 11(1), 11-20. https://doi.org/10.17509/ijal.v11i1.34614

\section{INTRODUCTION}

The sudden spread of COVID-19 triggered a wave of uncertainty in the educational arena and resulted in a complete closure of face to face, traditional classrooms at all levels of education - primary, secondary and tertiary stages, worldwide. Over time, many institutions in Bangladesh started taking initiatives to offer online classes with whatever resources and readiness they had. Nevertheless, stepping into cyberspace within a short span of time posed tremendous challenges for institutions, teachers as well as students in low resourced contexts. There were mixed reactions among different stakeholders (e.g., students, guardians, and teachers) in the media and online forums. Some described this move as inappropriate citing severe resource constraints and a lack of preparedness. Others stressed that there was no better alternative but to keep education going for the young generation. The suspension of classes for a couple of months since March 2020 was followed by a gradual move to providing online lessons to students. A leading English newspaper organized a forum discussion where participants consisting of teachers, students and administrators from different public and private universities expressed their hopes and fears regarding the transition to online classes (The Daily Star, 2020, July 17). The participants in

\footnotetext{
*Corresponding Author
}

Email: abashir@du.ac.bd 
general voiced their concern that neither the teachers nor the students were fully prepared to face this new normal reality because of contextual and technological constraints such as poor infrastructure, unstable connectivity mainly in rural areas, frequent power failures, lack of digital devices, and inadequate technological skills. They also expressed that there were uncertainties as to whether the teachers and students would have positive beliefs and attitudes towards this online mode of instruction. In this context, this study was conducted to explore the major challenges students of Bangladeshi public universities experienced in the emergency pandemic situation.

The basic requirements of successful implementation of online teaching are uninterrupted internet access and digital devices to connect with online classes. Access to the internet is a major challenge for people in developing and least developed countries. According to UNESCO, $47 \%$ of the population in developing countries are connected to the internet in contrast to only $19 \%$ in the least developed countries (Broom, 2020). The percentage of individuals using the internet in Bangladesh is as low as 13 (The World Bank, 2019). Those residing in cities and urban areas have better access to the internet than those living in the regions (Islam et al., 2020). Such discrepancies in access to the internet result in what is termed the 'digital divide' (Broom, 2020; Oyelaran-Oyeyinka \& NyakiAdeya, 2004). The digital divide concerns the existence of inequality or disparity among individuals, groups, communities and nations in accessing, distributing and using information and communication technologies (Castells, 2002; Norris, 2001; Van Dijk, 2006; Wilson, 2006). Beaunoyer et al. (2020) conceptualized digital inequalities as emerging from the differences in actual access to technology, as well as differences in digital literacy - the degree to which individuals have the capacity, knowledge, motivation, and competence to access, process, engage and understand the information needed to obtain benefits from the use of digital technologies, such as computers, Internet, mobile devices and applications. (p.1)

Lack of access and inequality were reported in a number of contexts around the globe. Patricia (2020) noted that students in many ethnic minority communities in the USA could not participate fully in online classes since they did not have enough supporting resources to understand course materials and do their tasks. As a result, the quality of the teaching learning process was much lower in online classes than that in on-campus classes. Sayer and Braun (2020) pointed out that inequality in accessing the internet and other technologies and inadequate support for learning English posed particular challenges for students from socioeconomically marginalized communities during COVID-19. Such inequality is evident in the educational context of Bangladesh, where a considerable proportion of students and teachers reportedly do not have access to technology resources in the truest sense of the term (The Daily Star, 17 July 2020). Van Dijk and Hacker (2003) mentioned four obstacles to learner participation in online classes: the absence of mental readiness, materials and connectivity, digital skills, and opportunities for usage. This paper aimed to explore, from the perspective of the students, the extent to which these barriers impede the implementation of emergency online instruction in the public universities in Bangladesh.

Affording the cost of the internet is also reported to be a challenge for students in many contexts including Bangladesh. The high cost of Internet use in Kenya and Nigeria, like many other African countries, is a major contributing factor for the exclusion of an overwhelming majority of the population from accessing the benefits of the internet and deteriorating the digital divide (Oyelaran-Oyeyinka \& NyakiAdeya, 2004). Students also suffered from a lack of internet connection at home to join online classes. Many students did not have personal computers and had to work from cafes. These constraints made it difficult for them to access course materials and do their tasks. They found the experience of online classes to be much less satisfying than that of face-to-face classes (Oyelaran-Oyeyinka \& NyakiAdeya, 2004). Alamgir (2020) has reported on the high costs of data packages and equipment in the context of Bangladesh that have put a strain on budgets of families. He points out that online education is inaccessible to many students, particularly to those in rural areas. The COVID-19 has thus exposed the 'digital divide' as one of the most striking inequalities among people across the globe (Broom, 2020). A digital divide involves unequal access to cyberspace and its benefits among groups or communities of people or certain regions within a country. It not only concerns access to material resources but also skills required for using the digital tools.

Some reported barriers to online instruction relate to pedagogy and materials. In order to enjoy the fullest advantages and unique affordances of online education, required changes should be made in pedagogy so that learning is enhanced (Stanley, 2019). Materials available for face-to-face classrooms such as printed books might prove inappropriate for the remote teaching contexts. Online instruction "may require specially-designed and written materials in order to take advantage of the teaching and learning context and delivery method" (Pintos, 2019, p.13). Therefore, educational institutions in different parts of the world have rapidly redeveloped their curriculum to suit the online mode of delivery in the pandemic situation (Crawford et al., 2020). Shin (2020), 
reviewing articles published in the TESOL Journal on contexts such as Hong Kong, Indonesia, Korea, and the U.S.A, pointed out that pedagogical endeavours could be instrumental in minimizing digital divides and promoting equity towards disadvantaged communities.

Assessment is integral to any teaching learning programme, and devising good assessment is always a challenge. Akimov et al. (2018) considered online assessment to be more challenging because traditional assessment does not suit online assessment, and therefore new assessment strategies need to be devised to fit in a distance teachinglearning environment. Other challenges of online assessment include plagiarism, collusion and cheating (Akimov \& Malin, 2020). Cheating has been reported to be a common problem in traditional face-to-face examinations in the context of Bangladesh. The risk of cheating is perceived to be higher in online tests as student examination behaviour cannot be proctored by teachers in person (Tarannum \& Azran, 2020). Online exam surveillance technology has been introduced in contexts such as Australia (Selwyn et al., 2021) but in the context of Bangladesh the application of such technologies may not be feasible as internet connections are unstable. The public universities in Bangladesh have not introduced online tests to date. Again, in order to ensure the quality and effectiveness of online assessment, a variety of assessment techniques (e.g. portfolios) are needed (Gaytan \& McEwen, 2007) which require teacher and learner training. Biggs and Tang (2007) commented that student learning is affected by what students think about assessment and the way they are assessed. Online assessment is therefore not a challenge for teachers only; it is also a matter of concern for students. Any fears that students might have about alternative modes of assessment should be identified and addressed.

Gillett-Swan (2017) pointed out that in online environment students may experience some personal challenges: "anxiety associated with using technology; being out of one's comfort zone; (perception of) inequity in assessment, particularly in group assignments; and, the (perceived) inability or difficulty in peer interaction, particularly in presentations" (p. 21). Due to limitations of the software and learning management system used for online classes both teachers and students may experience frustrations. Home environments also pose a challenge for students' attendance and participation in online classes (Gillett-Swan, 2017). Patricia (2020) conducted a study of 270 college undergraduate and graduate students in the US with a mean age of 21.9. She found that the students suffered from lack of concentration problems at home. She pointed out that the home environment was not congenial for attending classes as there were many distractions including family members, noise and housework. She found that students suffer from stress and troubles while learning online and completing their school tasks. Indonesian students reported that online teaching is more stressful than regular classrooms as they cannot socialise with friends (Angdhiri, 2020). Students' confidence and willingness in using technology are important factors. Bower (2019) contends that student learning outcomes may be affected if students lack confidence in using technology and are not emotionally involved to interact with peers in online classes.

Students' mental readiness is also an important factor for their engagement in online classes. The online instructional environment demands autonomous learning, self-discipline and selfmonitoring on the part of the students. Husu (2006) reported two psychological factors namely students' preference for the intimacy of face-to-face contact and inability or poor ability of some students to regulate or monitor themselves during learning tasks. Patricia (2020) noted that many students attending online classes displayed poor motivation and negative emotions. They also suffered from stress, anxiety, and fear of being attacked by coronavirus. Therefore, if online instruction is to be effective, students need to be provided with adequate training for independent learning. Research shows that for ensuring mutual engagement and collaboration among teachers and students, effective use of technology is needed (Botero et al., 2018; Bower, 2019). Teachers and students' intention and effectiveness of the technology may also play an important role to ensure a successful transition to online teaching and learning (Kemp et al., 2019).

Given the multifarious obstacles that tend to impede online education in different contexts, it was important to investigate what barriers came in the way of the successful implementation of the move to online mode of instruction in the Bangladeshi context. Therefore, this research attempted to focus on the perspectives of students, who are the main recipients of online education. The study addressed the following research questions:

1. What major challenges do students of English departments in the Bangladeshi public universities report facing in participating in online classes during the COVID-19 pandemic?

2. What strategies do students suggest for overcoming the challenges to online instruction?

\section{METHOD}

The aim of the study was to explore public university English department students' experiences of online classes during COVID-19 pandemic. For this purpose, a qualitative research design was adopted. 


\section{Data collection}

Semi-structured interviews were used to collect data from 26 students during the June-September 2020 period. The question prompts for the semi-structured interviews were originally composed in English and later translated into Bangla (mother tongue of the participants) for ease of understanding for students who may not be fully comfortable with English.

Two main interview questions were developed in line with the two research questions. The first main interview question explored the potential challenges the participants were facing in attending online classes, while the second one was aimed at eliciting suggestions they believed would be useful for overcoming those obstacles. A set of probing sub-questions were asked to glean in-depth information based on their responses. Prior to the interviews respondent consent had been sought over the phone followed by a written letter of consent for the interview by email. The interviews were conducted on the following online platforms: Zoom, Messenger and Google Meet, depending on the convenience of the participants. Of the 26 interviews, 8 were conducted via Zoom, 14 via Messenger, and 4 via Google Meet.

Each interview lasted approximately 30 minutes and was recorded with prior permission from the participants. Two of the four researchers conducted interviews each with 6 students and the other two with 7 participants each. The participants were given the choice to use either English or Bangla during the interviews. The aim was to ensure that they could speak freely without hesitation. It was noted that the participants responded mostly in English but occasionally switched to Bangla.

The researchers had initially contacted around 48 potential participants from the English departments of 11 public universities (4 from Dhaka, and one from each of the seven other divisions) across the country through emails which included an information sheet and a consent form detailing the purpose of the study and what they were supposed to do during the interview. Those who responded positively were contacted over the phone to confirm their availability. Out of 35 willing participants, 26 were finally selected for the interviews based on their gender, year of study and regional spread. We wanted to ensure an equal or near-equal spread in terms of gender, year of study and the regions they came from. The participants comprised 14 females and 12 males: 10 were masters level students and 16 were undergraduate students from the first year to fourth year. The participants were from eleven public universities located in eight divisions of the country: Dhaka (9 participants), Rajshahi (3), Rangpur (2), Mymensingh (2), Sylhet (2), Barishal (2), Khuna (3), and Chattogram (3). Since the dormitories were closed, the participants were at their homes in different districts of the country when they were interviewed. The students were aged between 19 to 23 years. 11 students were from urban and 15 from rural backgrounds. During the interviews, the students identified themselves as belonging to middle (11 students) and lower middle (15 students) socio-economic backgrounds.

\section{Data analysis}

The interview data were selectively transcribed and sections of the data in Bangla were translated into English. The interview transcripts were then read and cross-checked by another member in the research team for accuracy. The data were coded, categorised and analysed. A set of common themes related to the challenges the participants faced as well as suggestions they put forward were identified and reported. In order to maintain anonymity, the participants were coded as S1 to S26 and direct quotes have been reported accordingly.

\section{FINDINGS}

\section{Obstacles to online instruction}

The analysis of the interview data revealed a number of challenges related to successful implementation of online instruction in the COVID19 situation at the public universities in Bangladesh. The barriers identified from analysis of the interview data relate to access to technology resources, affordability, ability to use technology, pedagogy, online study materials, assessment, and equity.

\section{Lack of access and affordability}

Data revealed a lack of necessary devices to be one of the biggest challenges for the students to attend online classes. Before the pandemic, the students could make use of resources available in libraries and self-access centres in their Departments but now that they were at home they did not have access to these facilities. It was found that most of the students had mobile phones to join the classes, but only a few had laptops, desktops or notebooks required to carry out activities such as typing assignments and submitting via google classroom or e-mail, reading long articles and e-books online, and taking online examinations.

Supporting this, one student from the lower- middle socio-economic background commented:

I don't have anything except for a smartphone to attend online classes. Attending classes and doing assignments using a phone is really very tough. (S4)

Another student from the middle socioeconomic background stated:

I don't have any computer. I might be unable to work on my homework, assignment or presentation properly on time. (S10)

They also encountered problems while downloading large files and uploading assignments and other documents. One student commented: 
The first challenge I face is about consistency of internet service. Since the net service is poor, it is not possible for me to attend the classes properly. (S9)

If the internet connection is not stable, it is difficult for students to concentrate and understand the lecture. Due to unstable internet connection, students would often get disconnected, and sometimes they had to wait for a long time even to $\log$ in. This hampered their participation in online classes. Many of them relied on class recordings supplied to them after the class. One participant commented:

As $l$ have poor internet connection, I find it extremely challenging to attend online classes without any sort of disturbances. Trying to understand a lesson in an actual classroom is difficult. It requires a lot of concentration. I listen to the audio-recording of the lectures after the class when I get them but I miss the interaction of the live class. (S25)

\section{Cost of Internet connectivity}

Cost of internet data was also a matter of concern for the participants. In Bangladesh, most of the students in public universities come from middle and lower middle-income families. Purchasing data packages added to the financial burden the students were faced with during the pandemic. One participant stated:

As I come from a middle-class family, it is very difficult to avail the facilities. My father is the only working person in our family -- two of my sisters are studying in other universities. There isn't enough money to purchase data for all. (S6)

Another participant said:

I used to support myself by giving private tuition. Now I can't do that, and I have no income. What is worse, I need to buy 30 to $40 \mathrm{~GB}$ internet data for attending online classes, and that costs me around 800-1000 Taka. (S17)

\section{Lack of technological competence}

The students seemed to be confident about their own technological competence. However, they expressed concerns about their teachers' inadequate technological skills. They reported that some of the senior teachers were not very skilled in using apps like Zoom, Google Meet, and Google Classroom to conduct online classes. The following comments of the participants reflect their concern about teacher's technological skills:

I think I am quite good at using technology. ... But I find that some teachers have difficulty using online resources.... This is why online classes are not interesting. (S13)

All the teachers are not equally skilled; some even do not have the minimum skills to conduct an online class uneventfully. (S18)
As shifting to online classes was sudden and most teachers did not have any prior experience of online teaching before the pandemic, and did not receive adequate training, they encountered difficulties in delivering classes online at the initial stage of transitioning to online remote teaching.

\section{Challenges related to pedagogy and materials}

The interview data also revealed the participants' concerns regarding the lack of active participation in online classes and the unavailability of study materials. In face-to-face classes, students could participate in discussions, pair-work, and groupwork, but in online classes it is difficult for the teacher to engage all students in class discussion due to poor internet connectivity and large classes with 60 to 80 students. About class participation, one student commented:

Getting all of us to participate in discussions has been a challenge ... due to the large class size. The situation is made worse by unstable connections. It's nearly impossible for the teacher to involve everyone.... (S24)

Most students in public universities in Bangladesh come from across the country. With the sudden closure of educational institutions in March 2020, they left their residential halls and other temporary residences, and many of them could not bring study materials home. Many participants expressed this concern that they did not have the required materials for study.

As they were staying at home now and could not access their libraries, the participants counted this as a challenge for their studies. This is reflected in the following comment:

The seminar library of my department is very helpful [for finding related materials and resources]. As we do not have digital copies, finding study materials is quite a big challenge. (S3)

\section{Assessment-related concerns}

Students' attitudes toward online assessment were largely negative, and they voiced their concerns about the fairness of online assessment. They also viewed students' tendency to cheat and plagiarise as a major impediment. One student commented:

You can hardly have a fair assessment online. No teacher can ensure that students will be honest. Everyone wants a high CGPA. (S21)

Students viewed assessment in the current pandemic situation as 'questionable' (S12), 'unfair' (S6) and even 'impossible' (S19), citing various reasons that relate to exam preparation, students' feeling of comfort, and the potential adverse impact on their grades. Highlighting the problems in preparing for examination, one student noted:

Preparation for exams isn't possible. I left my books in my hostel. I can manage materials from the 
Internet but that won't be enough. Online exams seem almost impossible. (S3)

Students voiced their concerns about potential risk factors such as technical glitches, and possibility of unfair means. They were worried about their unreliable internet connection, and they felt that some of the students might adopt unfair means in online examinations as proctoring all students is difficult, and as a result, others might be affected.

Another student commented:

If online exams are introduced, my grades will be affected. Technological problems might affect my performance. I do not think I will be comfortable at all to sit for an online exam, as I will always be worried. (S25)

However, supporting online assessment, one student remarked:

Our friends in the private universities will go ahead and complete their degrees. We are falling behind. So we should not keep sitting...there must be exams. (S14)

\section{Psychological factors}

The participants expressed doubts if they were in the right frame of mind for the online classes. Ailments and deaths in the family and loss of income due to the pandemic were creating stress and anxiety and the students found it difficult to concentrate on studies. These issues came up in the following comment:

We can't get away from anxieties and stresses arising from the deaths and ailments of our relations, neighbours, and of the people across the country. Besides, this pandemic has ... affected the family income of many of us. It's hard to concentrate on studies. (S6)

Growing apprehension about survival during the COVID-19 situation was apparent in another student's comment:

One of my family members is already COVID-19 positive and she has been shifted to the hospital. I have to do a lot of household work cleaning, cooking, packing food to send it to the hospital. Is it physically possible for me to take more pressure at this point? When our survival is at stake, these online classes, quizzes, tests and assignments seem to be meaningless. (S7)

Students were also anxiety-stricken about their personal well-being and lack of proper space at home for online classes. Some thought that they were not comfortable interacting in online classes; some found themselves 'gradually losing interest' (S1), while there were others who missed the 'classroom spirit' (S16). They stated that they were bored sitting at home for such a long time and being unable to mingle with friends which they used to do before the pandemic.
Some reported 'anxiety caused by the new mode of teaching and learning' (S15). Unsuitable home environment posed a challenge for students' concentrating on studies, which is evident in the following comments:

A classroom setting and a domestic setting are totally different. It's easier to focus on the lectures of teachers in the classroom, but it is way more difficult to concentrate on the classes staying at home amid the anxieties of this pandemic. (S20)

With all the family members in the house and me sharing a room, it doesn't give me space to attend classes or study undisturbed. (S24)

All the challenges seemed to serve to reduce the motivation of both teachers and students for online classes. However, one participant thought online classes and exams actually helped to reduce anxiety by diverting the mind from the pandemic. She felt that students should not be thinking of the pandemic all the time. She commented:

[It's true] that it's difficult to focus [on studies]. But constantly worrying about the pandemic does not do any good. We need to keep classes and exams going. (S11)

\section{Suggestions for online instruction}

The participants in this study provided a number of important suggestions for effective implementation of online instruction in the public universities in Bangladesh during the pandemic. Their suggestions covering five different aspects of online education are discussed below.

\section{Ensuring access to resources}

Participants stressed that access to necessary resources such as smart devices and cheap internet data packages and financial support should be ensured for the insolvent students. They also suggested that the government and the university authorities should provide support to the needy students and ensure equity. One student stated:

As many students are underprivileged in our country, the cost of internet packs should be provided by the authorities. If possible, the university authority or the department should give the poor students some money to buy internet data packs. (S12)

Participants also expected the authorities to 'ensure high speed internet connection' (S20). They believed that teachers should also be provided with devices and technical support to improve the acoustics of the recorded videos.

\section{Enhancing technological competence of teachers and students}

The participants were concerned not only about their own lack of technological competence but also their teachers' lack of technological skills. Therefore, many participants suggested training for themselves 
as well as for teachers. They believe that if teachers are well trained for online teaching, students can learn easily from them. The need for teacher training becomes evident in the following comment:

We need training and technical support. Many of us do not feel confident enough. Teachers also need a bit of training as most of them are not that much familiar or comfortable with using technology. (S8)

\section{Addressing issues related to pedagogy and materials}

With regard to instructional strategies, students made a number of suggestions that reveal their awareness of innovative strategies. For example, the idea of a flipped classroom is not much heard of in Bangladeshi classrooms, but a student made the following suggestion: "Teachers can give us tutorial videos for preparation before an online class" (S1). Students seemed to favour small interactive classes too, which has not been a norm here. A student made the following remark: "The class should be a class of a few people and not like a plenary with 80 people" (S3). Students also highlighted the need for fun and enjoyment:

Online instructors should have an appropriate sense of humour so that the classes aren't boring. If we can't enjoy the lessons, we won't be able to learn. (S19)

Teachers should try to make their delivery as engaging and interesting as possible because students' attention spans mostly depend on the lecturer's oratory skills. (S10)

Regarding teacher behaviour, participants suggested that teachers need to be more friendly, accommodating, cooperative and empathetic to students. One participant noted:

Teachers should ensure more cooperation. They should be easily accessible so that students feel free to share their problems with them. ... Students will get demoralized if teachers maintain their studentteacher distance. (S24)

Regarding materials, the participant suggested that teachers should provide them with necessary materials because they do not have access to libraries as they are staying at home now and most of their texts are not available online. The participants generally believed that recordings of class lectures were very useful. One student stated: "It is helpful when teachers record and upload their classes on an easy access site" (S25).

\section{Modifying the existing assessment system}

Most of the participants were apprehensive about online assessment as they believed that their performance might be affected. In traditional faceto-face classes, the final assessments are usually done through 3 to 4 hour long sit-down written examinations. For online assessment no decisions or guidelines have been provided by the public university authorities yet. Most participants in their interviews expressed concerns and suggested various modifications to existing assessment systems. As one participant pointed out, "Oral examination is the way to go" (S2).

Another suggested avoiding setting "simple exams" measuring low-order thinking and instead give the students "critical and analytical questions as their exams or assignments (S15). One student believed that assessment should be postponed until everyone went back to the campus:"Teachers should give quizzes and assignments after lockdown because some don't have equipment at home...some are not habituated to submitting assignments online" (S17).

\section{Dealing with psychological issues}

Participants revealed that many were experiencing psychological issues during the pandemic and emphasised that "all types of tension and ambiguity should be removed from our mind ...otherwise, we won't be able to focus on studies" (S10). They suggested that the department should introduce student counselling service and teachers should adopt a flexible approach to teaching to ease the pressure. One participant commented:

Teachers should be more friendly and considerate about the problems students are facing in this pandemic. They should focus on reducing students' anxiety and boosting up their mental strength. (S23)

\section{DISCUSSION}

The study explored the challenges that English major students at the public universities in Bangladesh encountered while attending online classes during the COVID-19 pandemic, and their suggestions to overcome the barriers. The findings revealed that the main challenges to remote teaching and learning were related to lack of appropriate devices, poor internet connectivity, high cost of internet data and lack of technological competence of both students and teachers. In addition, difficulty in class participation, insufficient online materials, apprehensions about online assessment were other factors contributing to reluctance, dissatisfaction and anxiety.

As the findings indicate, lack of laptops and desktops is a major obstacle to online instruction in Bangladeshi public universities. Another major impediment is poor internet connectivity mainly in the rural areas. Smooth functioning of online classes requires uninterrupted and strong internet connection. In Uruguay, for example, the availability of fibre-optic cable connections with identical upload and download speeds resulted in fewer classes being cancelled or interrupted (Stanley, 2019). Internet speed in Bangladesh varies greatly from place to place. In some areas, mobile internet is reported to be extremely poor (Kamal et al., 2020). The participants in this study expressed 
their concerns regarding unsteady internet connectivity. Due to the poor internet speed, many of them could not listen properly and at length to the deliberations of their teachers and peers during online classes, as they frequently got disconnected either due to power cuts or unstable internet connections. Similar situations have been reported in studies in other contexts. For example, in the context of Indonesia, Angdhiri (2020) points out that there are students who did not possess required devices and internet access to participate in online classes during the pandemic, and so they suffered more than others. There seems to be very little that students, their parents or teachers can do in this regard. The university authorities might do well to approach the government to work with the mobile phone operators and other internet providers to build infrastructural facilities and ensure faster broadband connectivity.

The participants also identified the high cost of internet data as another challenge. Most of the students in public universities in Bangladesh generally come from a lower-middle and middleclass background. The data show that the cost of internet data is an additional burden for the students and their families. A student has to spend on an average TK 800-1000 (10-12 USD) to buy internet packages. It is important to note that many students at the public universities in Bangladesh maintain their educational expenses as well as support their families through private tutoring. When the pandemic broke out and all educational institutions were closed, students had to leave their residential halls, thus losing their sources of income. It is to be noted that there was no subsidy or special offer for internet data for students as a whole to attend online classes. A few universities took initiatives to enter into a contract with private mobile operators for special data packages for their students, but it did not materialize. Since a significant number of students were unable to attend classes owing to the lack of devices and poor connectivity, online classes have clearly brought issues of inequity to the fore. Although digital divide had already existed in different strata of society in Bangladesh before the spread of COVID-19, its adverse impact on education had never been so deeply felt as in the wake of the pandemic. Such disparities in access to the internet lead to a 'digital divide' (Broom, 2020; Oyelaran-Oyeyinka \& NyakiAdeya, 2004).

Students were also concerned about the lack of study materials and proper environment for attending classes and studying at home. Lack of a proper environment at home has been reported to be a major hurdle to attending online classes in other contexts too, such as in China (Bao, 2020) and the USA (Patricia, 2020). The findings also show students' concerns about not being able to access necessary materials for their study. As they were now staying at home, they could not access the libraries in person. Moreover, much of their study/course materials were not available in soft copies. Students' lack of satisfaction with online classes might be related to teachers' lack of skills in using technological resources and providing students with appropriate materials and tasks. It has been argued that teachers' need training to learn to use new technology resources and to improve student learning in online classes (Preston, 2017). The findings revealed that many teachers lacked skills to use technological tools and conduct online classes at the initial stage of transitioning to online classes when the study was conducted. If the teachers cannot use technology tools efficiently and with full confidence, it might cause student demotivation and disengagement.

Findings also reveal students' apprehension about online examinations. They were not sure about the modalities of online assessment and were worried about their performances in online examinations. They raised their concerns that some of the unscrupulous students might adopt unfair means in online examinations and thus their ranks could be affected. Online assessment is new in the context of Bangladesh. Before the pandemic there was no provision for online examinations. Therefore, neither the students nor the teachers had any prior experience of online assessment. The public universities had initiated small-scale assessment through assignments when data were being collected. The semester final examinations have, however, been withheld since the pandemicinduced closure. A decision has been taken to start semester final examinations at public universities from July 2021 if the current pandemic situation persists (The Daily Star, 2021, May 6). It is important to take student worries and concerns regarding online examinations into consideration and prepare them through trial or mock tests. Additionally, the universities should arrange counselling and discussion sessions to address issues of students' anxiety, stress and apprehension to allay their fears.

\section{CONCLUSION}

This study captured students' voices on the implementation of online instruction during the pandemic at the public universities in Bangladesh. The study presented their views on the barriers they faced in participating in online classes as well as their suggestions to overcome those barriers. The major obstacles indicated by the study findings include lack of access to devices and connectivity issues, high costs of internet data, lack of technological competence, unavailability of materials, large classes and limited opportunity for interaction. Other challenges highlighted were lack of trust in delivering online assessment, and low motivation levels. There were a range of suggestions 
from students for overcoming the challenges. Firstly, access to resources needs to be ensured to enable all students to participate in this new mode of teaching and learning. Secondly, both teachers and students require training to enhance their technological competence. Thirdly, appropriate pedagogical strategies and assessment procedures need to be practiced to ensure effective online teaching and learning. Fourthly, the curriculum needs to be adapted to fit the online mode. Finally, students' psychological problems during the pandemic situation should be addressed. Students also stressed that the quality of education should not be compromised in the process of making the necessary changes and adjustments in pedagogy and instruction.

The findings of this study may be useful for those responsible for formulating educational policies, the administrators of universities and the University Grants Commission (UGC), which is the main regulatory body for all universities in Bangladesh, as well as for the educational leaders of Bangladesh. The barriers identified in this study need to be addressed for the smooth operation of ongoing remote teaching at the public universities in Bangladesh. The suggestions provided by the student participants may be given due consideration while planning appropriate measures.

The findings reported in this paper represent the challenges students came across in the early phase of online classes. Follow-up studies may explore what measures have been adopted for the successful implementation of online teaching and learning. Such studies could employ multiple data sources to investigate which strategies have proved effective; which of the problems have been successfully dealt with and which ones still persist and need addressing at the tertiary-level of education in Bangladesh.

\section{REFERENCES}

Akimov, A., \& Malin, M. (2020). When old becomes new: a case study of oral examination as an online assessment tool. Assessment \& Evaluation in Higher Education, 45(8), 12051221. https://doi.org/10.1080/02602938.2020.173030 1

Akimov, A., Kobinger, S., \& Malin, M. (2018). Determinants of Student Success in Finance Courses. Journal of Financial Education. 44 (2), 223-245.

Alamgir, M. (25 July 2020). Cost of online classes: Extra burden on parents, teachers. The Daily Star. https://www.thedailystar.net/frontpage/news/co st-online-classes-extra-burden-parentsteachers-1935773
Angdhiri, R. P. (2020). Challenges of home learning during a pandemic through the eyes of a student. The Jakarta Post.

https://www.thejakartapost.com/life/2020/04/1 1/challenges-of-home-learning-during-apandemic-through-the-eyes-of-a-student.html

Bao, W. (2020). COVID-19 and online teaching in higher education: A case study of Peking University. Human Behaviour and Emerging Technologies, 2(2), 113-115. https://doi.org/10.1002/hbe2.191

Beaunoyer, E., Dupéré, S., \& Guitton, M. J. (2020). COVID-19 and digital inequalities: Reciprocal impacts and mitigation strategies. Computers in Human Behavior, 111. https://doi.org/10.1016/j.chb.2020.106424

Biggs, J., \& Tang, C. (2007). Teaching for quality learning at University: What the student does. Open University Press/McGraw-Hill Education.

Botero, G. G., Questier, F., Cincinnato, S., He, T., \& Zhu, C. (2018). Acceptance and usage of mobile assisted language learning by higher education students. Journal of Computing in Higher Education, 30(3), 426-451. https://doi.org/10.1007/s12528-018-9177-1

Bower, M. (2019). Technology-mediated learning theory. British Journal Education Technology, 50(3), 1035-1048. https://doi.org/10.1111/bjet.12771

Broom, D. (2020). Coronavirus has exposed the digital divide like never before. We Forum. https://www.weforum.org/agenda/2020/04/cor onavirus-covid-19-pandemic-digital-divideinternet-data-broadband-mobbile/

Castells, M. (2002). The internet galaxy: Reflections on the internet, business, and society. Oxford University Press.

Crawford, J., Butler-Henderson, K., Rudolph, J., Malkawi, B., Glowatz, M., Burton, R., \& Lam, S. (2020). COVID-19: 20 countries' higher education intra-period digital pedagogy responses. Journal of Applied Learning \& Teaching, 3(1), 1-20. https://doi.org/10.37074/jalt.2020.3.1.7

Gaytan, J., \& McEwen, B. (2007). Effective online instructional and assessment strategies. American Journal of Distance Education, 21(3), 117-132. https://doi.org/10.1080/08923640701341653

Gillett-Swan, J. K. (2017). The challenges of online learning: Supporting and engaging the isolated learner. Journal of Learning Design, 10(1), 2030. https://doi.org/10.5204/jld.v9i3.293

Islam, M. S., Tanvir, K. M., Amin, M., \& Salman, M. (1 June 2020). Online classes for university students in Bangladesh during the Covid-19 pandemic- is it feasible? The Business Standard. https://www.tbsnews.net/thoughts/online- 
classes-university-students-bangladesh-duringcovid-19-pandemic-it-feasible-87454

Kamal, R. S., Mithu, A. I., \& Hossain, M. (2020). When your internet can't keep pace with. Digital Bangladesh. https://tbsnews.net/feature/panorama/whenyour-internet-cant-keep-pace-digitalbangladesh- 123850

Kemp, A., Palmer, E., \& Strelan, P. (2019). A taxonomy of factors affecting attitudes towards educational technologies for use with technology acceptance models. British Journal Education Technology, 50(5), 2394-2413. https://doi.org/10.1111/bjet.12833

Husu, J. (2006). Access to equal opportunities: building of a virtual classroom within two 'conventional' schools. Journal of Educational Media, 25(3), 217-228. https://doi.org/10.1080/13581650020054398

Norris, P. (2001). Digital divide: Civic engagement, information poverty, and the internet worldwide. Cambridge University Press.

Oyelaran-Oyeyinka, B., \& NyakiAdeya, C. (2004). Internet access in Africa: Empirical evidence from Kenya and Nigeria. Telematics and Informatics, 21(1), 67-81. https://doi.org/10.1016/S0736-5853(03)000236

Patricia, A. (2020). College students' use and acceptance of emergency online learning due to COVID-19. International Journal of Educational Research Open, 1(2020). https://doi.org/10.1016/j.ijedro.2020.100011

Pintos, V. (2019). Materials design for remote language teaching. In G. Stanley (Ed.). "Remote teaching" digital language learning and teaching: Research, theory, and practice. British Council.

Preston, C. (2017). Hardwired to learn. Education Executive. Retrieved 10th June, 2020, from http://edexec.co.uk/hardwired-to-learnprofessor-christina-preston-onedtech-andattainment

Sayer, P., \& Braun, D. (2020). The disparate impact of COVID-19 remote learning on English learners in the United States. TESOL Journal, 11(3), e00546. https://doi.org/10.1002/tesj.546

Selwyn, N., O’Neill, C., Smith, G., Andrejevic, M., $\& \mathrm{Gu}, \mathrm{X}$. (2021). A necessary evil? The rise of online exam proctoring in Australian universities. Media International Australia,116. https://doi.org/10.1177/1329878X211005862

Shin, D-S. (2020). Introduction: TESOL and the COVID-19 pandemic. TESOL Journal, 11, e547. https://doi.org/10.1002/tesj.547

Stanley, G. (2019). Introduction to remote language teaching. In G. Stanley (Ed.). "Remote teaching" digital language learning and teaching: Research, theory, and practice. British Council .

Tarannum, S. A., \& Azran, A. (2020, December 3). Why students cheat. The Daily Star. https://www.thedailystar.net/shout/news/whystudents-cheat-2004993

The Daily Star. (6 May 2021). UGC allows online exams for public universities. The Daily Star . https://www.thedailystar.net/bangladesh/news/ ugc-allows-online-exams-public-universities2089353

The Daily Star. (2020, July 17). Online classes: Increasing the education divide. Retrieved from:

https://www.thedailystar.net/opinion/news/onli ne-classes-increasing-the-education-divide1931409

The World Bank. (2019). Individuals using the internet (\% of population) - Bangladesh. https://data.worldbank.org/indicator/IT.NET.U SER.ZS? end=2019\&locations=BD\&most_rece nt_year_desc $=$ false \&start $=1990 \&$ view $=$ chart

Van Dijk, J. (2006). The network society: Social aspects of new media (2nd ed). SAGE.

Van Dijk, J., \& Hacker, K. (2003). The digital divide is a complex, dynamic phenomenon. The Information Society, 19(4), 315-326. https://doi.org/10.1080/01972240309487

Wilson, E. J. (2006). The information revolution and developing countries. MIT Press. 